\title{
Falas da diferença: aconselhamentos e modos de ser kanhgág pé
}

\author{
PAOLA ANDRADE GIBRAM
}

UNIVERSIDADE DE SÃO PAULO (USP), SÃO PAULO/SP, BRASIL

HTTPS://ORCID.ORG/0000-0003-4369-8675

\section{Apresentação ${ }^{1}$}

A compreensão da centralidade da fala nos mundos indígenas tem se tornado assunto inescapável. A busca por um aprofundamento reflexivo acerca das políticas ameríndias tem-nos levado à percepção de que atos de fala são epicentros na construção de chefias, pessoas, coletivos. Falar, nestes contextos, não está ligado apenas ao plano comunicativo. Percebe-se, com suas devidas variações, que o ato de fala está ligado à construção de pessoas e corpos, a agências transformadoras do mundo, a processos de cura, ao manejo de forças e potências, à criação de vínculos com seres humanos e não humanos.

Este texto busca trazer contribuições sobre modos específicos de fala dos Kaingang - povo indígena cuja língua pertence ao tronco macro-jê, e que é classificado, com os Xokleng, como o grupo dos Jê Meridionais. Trago aqui algumas descrições e reflexões a partir do que eu tenho aprendido ao longo de dez anos de convívio intermitente com interlocutores kaingang de diferentes regiões sobre a importância e o estatuto dos aconselhamentos, falas proferidas por pessoas detentoras do que concebem como conbecimento dos antigos. Darei ênfase ao que aprendi na Terra Indígena Rio da Várzea, localizada no noroeste do Rio Grande do Sul, onde passei mais tempo durante minha pesquisa de mestrado (Gibram 2012,2016). Trarei também notas sobre o que tenho aprendido com Gilda Kuitá, liderança

1 Este artigo foi escrito com o apoio da Fundação de Amparo à Pesquisa do Estado de São Paulo (FAPESP), referente ao processo de número 2017/17743-7. 
kaingang que reside atualmente na Terra Indígena Apucarana (PR), onde é uma das mentoras do coletivo de jovens indígenas denominado $N e \tilde{n} G a^{2}$.

Devo ressaltar que meu aprendizado sobre a potência da oralidade entre os Kaingang ganhou especial aprofundamento com a escuta da fala de Gilda Kuitá no Seminário "Lições de fala - diálogos ameríndios", que ocorreu na USP no início do mês de julho de 2018. Considerada uma kofá [pessoa mais velha, anciã, considerada por isso, mais sábia], sua fala - como sempre perspicaz e fina em humor - mostrou-se ali também como uma forma de aconselhamento, como veremos.

\section{Linguagem, política e estética indígena: um breve panorama}

Como inicialmente mencionado, o tema das falas formais indígenas, bem como dos cantos, das danças e das pinturas, tem ganhado um crescente investimento em pesquisas recentes de etnologia americanista. Isso se deve - em grande parte, mas não apenas - à percepção de que as políticas indígenas não podem ser pensadas de forma isolada de suas formas expressivas. Em outras palavras, o que se percebe não apenas em contextos contemporâneos, mas também no corpus de etnografias que abordaram o problema do político entre os coletivos ameríndios, é que não existe ação política indígena descolada de falas de chefe, diálogos cerimoniais, cantos, danças, pinturas, ornamentações.

Minha experiência junto aos Kaingang (cf. Gibram 2008, 2012, 2017) desdobrou-se justamente neste corpus de questões que se mostra pertinente a outros coletivos ameríndios - refiro-me aqui especialmente às etnografias que se detiveram no problema do político, alargando as contribuições de Clastres (2003[1963]; 2004 [1976]) sobre o tema. Tratam-se das questóes decorrentes da inseparabilidade entre política, linguagem e estética - o que é claramente percebido no vínculo entre chefia e o "dever da palavra", bem como nas inúmeras "formas linguágicas"3 (cf. Menezes Bastos 2013) vinculadas às ações políticas e diplomacias engendradas pelas lideranças indígenas.

Por outro lado, veremos que, assim como tem-se percebido em outros contextos indígenas, o estatuto das falas formais kaingang extrapola o plano referencial e aponta para o plano pragmático da linguagem: são palavras faladas que constroem mundos, vínculos, modificam corpos, condutas. Além disso, apontam para formas de conexão e atenção específicas e formas de relacionalidade que escapam a olhares limitados ao plano das interações humanas. Assim, faz-se necessário sinalizar de início o fato de que, entre os Kaingang e muitos outros povos indígenas, as falas formalizadas - nas quais se incluem as falas de chefe e os aconselhamentos - são aprendidas não apenas pela escuta dos mais velhos ou pela experiência como liderança, mas também por meio de relações cuidadosas com seres demiurgos, ancestrais,

2 Tenho acompanhado o coletivo Nén Ga durante minha pesquisa de doutorado, trabalhando questôes referentes à transmissão de saberes, formas expressivas e ações políticas. Gilda Kuitá tem sido uma das minhas mais importantes interlocutoras nesse processo.

3 Considero falas, cantos, danças, pinturas, ornamentações como linguagens, procurando dar ênfase ao que Menezes Bastos (2013) definiu como qualidade "linguágica" dessas formas comunicativas - ainda que, seguindo a proposta de Taugny (2013), eu não as considere apenas em seu plano comunicativo. Segundo Menezes Bastos (2013), esta qualidade aponta para linguagens não restritas ao domínio verbal (que, por sua vez, pertenceriam ao domínio da "linguística"), mas a todo campo semiológico o que entende ser congruente com a ideia de que a semiótica é uma ciência geral - e não especifica à linguística - dos sistemas de signos. 
ou com espíritos de outras gentes: animais, plantas, rios, montanhas. Antes de adentrar no mundo kaingang, trago alguns fragmentos etnográficos que embasam as generalizações aqui esboçadas.

Um belo exemplo da interligação da linguagem (incluindo não apenas a verbal) com planos extrahumanos nos vem com os Guarani Mbyá, os quais aprendem a alma-palavra (nhe’e) ao dançar e cantar por longos períodos, tornando seus corpos mais leves e aptos a se elevar aos deuses. Assim, falar as belas palavras, para os Guarani, seria comunicar-se diretamente com Nhanderu e vencer os paradoxos de ser uma coisa ou outra - pois, justamente, as belas palavras fazem dos Guarani ao mesmo tempo humanos e deuses (cf. Clastres, H., 1975).

Outro exemplo profícuo é encontrado entre os Kĩsêdjê. Segundo Seeger (2014), os cantos rituais entre esses indígenas são aprendidos pelos xamãs, os quais, por terem o espírito desprendido do corpo, tornam-se aptos ao deslocamento até o mundo dos espíritos dos animais, com os quais aprendem o repertório ritual específico dos cantos akia e ngere. Esses cantos, considerados como o tipo de comunicação mais formalizada entre os Kĩsêdjê, são o cerne das performances rituais, por sua vez fundamentais para a construção da pessoa e dos coletivos sociopolíticos, assim como em outros contextos ameríndios. Cumpre ressaltar que a etnografia de Seeger (2015), além disso, aponta para uma continuidade entre os diversos gêneros de fala e os cantos kĩsêdjê, os quais são diferenciados por parâmetros formais de autoria e não pela presença ou ausência de variação melódica. Sua abordagem abrangente das "formas artísticas vocais" leva à apreensão das estéticas vocais kĩsêdjê em relação às diferenças de idade, status social e político, à corporalidade, bem como às relações com seres não humanos, aos quais, como mencionado, atribui-se a autoria dos cantos.

Destaco também o paralelo percebido entre os Yanomami, pautando-me nas inúmeras formas como Davi Kopenawa (Kopenawa e Albert 2010) descreve e ressalta o conhecimento profundo aprendidos pelos xamãs por meio de suas relações com os espíritos xapiri, com os quais se comunicam pelos sonhos e pela ingestão do pó de yãkuana. Os diálogos cerimoniais, as falas e os cantos das festas de reahu - principal evento inter-aldeão yanomami, nos quais anfitriões consolidam relações de amizade com grupos de inimizade latente - são formados por palavras dadas pelo demiurgo Omama àqueles que aprendem a estabelecer vínculos com esses seres espirituais em sonhos:

\footnotetext{
"Para nós, a política é outra coisa. São as palavras de Omama e dos xapiri que ele nos deixou. São as palavras que escutamos no tempo dos sonhos e que preferimos, pois são nossas mesmo. Os brancos não sonham tão longe quanto nós. Dormem muito, mas só sonham com eles mesmos. Seu pensamento permanece obstruído e eles dormem como antas ou jabutis. Por isso não conseguem entender nossas palavras". (Davi Kopenawa apud Kopenawa e Albert 2010:390)
}

Davi explica ainda que as falas destinadas aos brancos são um desdobramento desse conhecimento adquirido, uma transformação da fala de chefe conhecida como hereamuu. Assim como este gênero de fala, as falas proferidas por Davi aos brancos são formadas por palavras que penetram fundo no pensamento, devendo por isso serem levadas aos brancos para que as ouçam e as entendam; antes que todos, índios e brancos, morram com a queda do céu (cf. Kopenawa e Albert 2010: 376-384).

Diante deste breve panorama, voltemos aos Kaingang. 


\section{Mestres da fala, da escuta e do silêncio}

Em minha convivência com os Kaingang, aprendi a importância do silêncio. Não se fala, entre eles, quando não se tem algo realmente importante a se dizer. O silêncio é a chave para a potência da fala. Aqueles que sabem falar, que sabem aconselhar, não falam qualquer coisa, nem em qualquer ocasião. São consideradas pessoas sábias, detentoras do conhecimento dos antigos, e geralmente também do que chamam de conhecimento do mato. São pessoas, portanto, que souberam ouvir o que os antigos ensinaram por meio de suas falas. E, em muitas das vezes, souberam também ouvir o que os espíritos da floresta têm a dizer - sendo, também, portanto, mestres do silêncio.

Conversando com alguns kofá [pessoas mais velhas, anciãs] - destaco aqui o falecido Sr. João Elias da TI Rio da Várzea, bem como o renomado kujá [xamã kaingang] Jorge Garcia, residente da TI Nonoai - aprendi que as falas importantes (ou formais, nas quais se incluiriam os aconselhamentos e as falas públicas do cacique) remetem a relações que também abrangem planos extrahumanos. Especificamente no contexto da TI Rio da Várzea, salienta-se que para que alguém possa ser på [chefe, líder ou "cabeça"], é necessário que se adquira não apenas o conhecimento de liderança, mas também o conhecimento do mato, o qual é veiculado desde o tempo dos antigos - expressão pela qual traduzem o termo vãsy. Só assim a pessoa torna-se apta a falar devidamente a sua própria comunidade, bem como apta a proferir aconselhamentos.

Antônio Moreira, então cacique da TI Rio da Várzea, ao apresentar-me sua trajetória e formação como liderança, destacava sempre a importância de ter conjurado aspectos do conhecimento de liderança, com o conhecimento dos antigos e o conhecimento do mato. $\mathrm{O}$ conbecimento da liderança foi por ele e por outras lideranças kaingang a mim definido como aquele referente a saber falar em público, conhecer bem o sistema das leis internas indígenas, e possuir certo domínio sobre o sistema do branco, principalmente no que diz respeito às políticas públicas e ao sistema legislativo. Segundo diversos interlocutores, esses conhecimentos seriam adquiridos processualmente, a partir da experiência como lideranças menores (pa’i sî), chegando às lideranças maiores ( $p \tilde{a} i$ mág).

A aprendizagem dos conhecimentos do mato, segundo interlocutores de diversas aldeias kaingang, é atribuída à capacidade de se ouvir a floresta e os seres/ espíritos que nela habitam. Dentre estes seres, destacam-se os jagrẽ, que são traduzidos, dependendo da região, como guias, espíritos-guia, mestres da mata ou encantados. A comunicação com esses seres demanda a construção e a manutenção de relações de grande atentividade, em grande parte associadas à capacidade de estar em silêncio e saber ouvir. Saber ouvir os rios, os pássaros, as árvores, os animais é o que possibilita que o próprio espírito possa se comunicar com o jagrê de cada um desses seres. A fala de Jorge Garcia é iluminadora quanto a isso:

"Cada mestre índio tem um tipo de trabalho. Porque o nosso mestre da mata, que nós trabalhamos, não é igual um ao outro. Todas as coisas têm espírito: o céu tem o comandante dele, o sol, a lua, as estrelas, a mata também. Dependendo do pensamento do mestre da mata, ele conta no sonho o trabalho que tem que fazer (...). Eu trabalho com uns três, quatro guias... hoje cedo ainda veio bem no raiar do dia um, o gavião penacho. Mas é o guia do gavião penacho que vem. Têm vários tipos de guia, a águia, a onça... mas não é o próprio bicho. É o espírito que comanda aquele bicho que vem vocar na gente, pra gente ter sabedoria lá da mata. Por isso eu digo: lá na mata a gente conhece 
tudo: eu falo com os passarinhos, eu falo com as madeiras... sei dos bugios, quando estão fazendo a reunião deles, eu sei o que eles estão fazendo, o que eles estão falando... pelo guia deles também." (S.

Jorge Garcia, maio de 2015).

Tais vínculos e relações, devo destacar, são vivenciados de formas gradativas: ainda que existam especialistas que se aprofundem nos conhecimentos do mato - como os $k u j a^{4}$, os curandeiros e as benzedeiras - o conhecimento dos poderes das plantas e dos remédios do mato [vénh kagta] é amplamente difundido entre os Kaingang, principalmente entre as mulheres (cf. Gibram 2016: 87). E, de forma geral, o conhecimento do mato é associado ao conhecimento dos antigos, estando relacionado a uma forma de ser, de viver, como kanhgágpé (verdadeiramente indígena/ verdadeiramente kaingang). Especificamente na TI Rio da Várzea, diz-se que não se pode ser liderança sem que a pessoa saiba se portar como um kanhgágpé.

Os conhecimentos dos antigos são, por sua vez, transmitidos inter-geracionalmente. Essa transmissão de conhecimentos faz parte da criação dos filhos, por meio das falas dos mais velhos (nas aldeias do Rio Grande do Sul os kofá são referidos também como troncos-velhos) aos mais novos, principalmente entre as figuras dos avós e seus netos e bisnetos. $\mathrm{O}$ ambiente mais propício para a transmissão de conhecimento dos antigos no âmbito doméstico é a în sĩ [casa pequena], a casa de fogo, localizada geralmente ao lado das casas residenciais, onde os troncos-velhos reúnem-se para conversar com pessoas de seus núcleos familiares e com visitantes. Por não "ser da palavra escrita" (conforme sempre me falava), o cacique de Rio da Várzea sempre reafirmava seu domínio sobre o conhecimento que "sabe de memória e aprendeu com os avós". Acrescentou-me certa vez que "quem escutar o que eu digo, vai estar aprendendo esse conhecimento. E o que eu digo hoje vai ser a mesma coisa que eu vou dizer daqui a 20, 30 anos" (Antônio Moreira, TI Rio da Várzea, março de 2011).

Por outro lado, a transmissão de conhecimento dos antigos é também feita de forma mais formalizada, em âmbitos públicos e em ocasiões específicas, por meio de aconselhamentos feitos por especialistas. Na TI Rio da Várzea, a liderança - formada por cacique, vice-cacique, coronel e capitão (lideranças maiores), e por major, cabos e polícias (lideranças menores) - era formada também por dois destes especialistas, conhecidos como conselheiros. Tratava-se de dois anciãos, que possuíam uma participação primordial nas tomadas de decisões, por serem justamente detentores do "conhecimento das leis e dos costumes dos antigos". Eram eles os responsáveis por aconselhar as pessoas que haviam errado ${ }^{5}$ ou seja, infringido alguma das leis internas, devendo por isso receber algum tipo de condena $a^{6}$.

\footnotetext{
4 Veja-se que, segundo Crépeau $(1997,2002)$, os poderes e o conhecimento do kujá são recebidos através de animais-guia, instrutores para os momentos de caça e de cura, com os quais entra em contato na floresta, construindo uma forte ligação através de uma série de atividades específicas a cada animal. O guia mais comum encontrado entre os kujá é a jaguatirica e o gato-do-mato, também conhecidos como "tigre". No entanto, encontram-se também comumente kujá que têm como guias alguns santos católicos. Para uma lista comparativa de kujá e seus respectivos guias em diferentes TIs kaingang, ver Rosa (2005: 143-151).

5 Os Kaingang de Rio da Várzea não utilizam a palavra "crime" para os delitos cometidos internamente - utilizam erro. Por outro lado, algumas vezes eles usaram o termo "crime" para se referir aos delitos condenados pela "justiça dos brancos". Os termos relacionados a esses sistema de punições são, em sua maioria, proferidos em português (no contexto da TI Rio da Várzea, saliento). No contexto das TIs do Tibagi, da qual destaco a TI Apucaraninha, usa-se também a palavra kygnẽ para o erro ou para o ato de errar (conforme também apontado por Ramos 2008: 55).

6 Forma como se referiam às punições locais, como a cadeia, o tronco, os trabalhos comunitários, ou em casos mais sérios, a transferência daquela TI. A palavra que traduzem erro para kaingang é kygnẽ. Os termos, no entanto, relacionados a esse sistema de punições são, em sua maioria, proferidos em português.
} 
Veja-se que a expressão leis internas é a forma como os Kaingang de muitas regiões referem-se às normas locais que orientam formas de conduta consideradas ideais (cf. Gibram 2012, 2016). A este respeito é importante destacar a pesquisa de Ramos (2008), realizada nos territórios indígenas kaingang da bacia do Tibagi ${ }^{7}$, na qual destaca-se que a categoria jykré seria o equivalente a lei, e também a cultura, sistema ou costume $e^{8}$. Segundo a autora, esta categoria - jykré - e a categoria ki ha han ke - a qual traduz como "fazer a coisa certa", "proceder da maneira correta" ou "obrigação" (:154) - seriam centrais para a formulação daquilo que descreve como "sistema jurídico kaingang":

"Em Kaingang, jykré refere-se às regras menos flexíveis e aos comandos gerais e impessoais. Assim, éjykré todo ordenamento determinado culturalmente, como por exemplo o contido nos mitos, ou emanado de agente legítimo, tanto de fazer quanto de não fazer. [...] Ki ha han ke, por outro lado, refere-se aos atos e comportamentos ideais, sobretudo em relação à sexualidade, aos parentes, aos chefes, aos co-cidadãos etc." (Ramos 2008: 153)

No contexto de Rio da Várzea, a expressão leis internas, em português, era usada com bastante frequência, mesmo quando se falava em kaingang. Conforme foi-me explicado, essas leis existem desde o tempo dos antigos ${ }^{10}$, ainda que exista em relação a elas um grau forte de inovação, de acordo com as necessidades contemporâneas da comunidade ${ }^{11}$. Quando se tem que elaborar alguma nova lei, esta é elaborada pelas lideranças maiores, comunicada às lideranças menores e passa a ser efetivada após a aprovação da comunidade. Baseado nessas leis, o capitão pode mandar as lideranças menores prenderem aquelas pessoas que tenham errado. Em Rio da Várzea, as leis internas são transmitidas oralmente ${ }^{12}$, fazem parte da tradição e do costume dos antigos e se coadunam com o conteúdo dos aconselhamentos proferidos pelas lideranças.

\section{O que faz um aconselhamento}

Os aconselhamentos formais, ou seja, aqueles proferidos pelos conselheiros da liderança, são imprescindíveis ao sistema das leis internas e às diferentes formas de condena - termo utilizado, como vimos, às práticas punitivas destinadas a pessoas que tenham desviado sua conduta dos padrões morais

7 Trata-se de cinco TIs localizadas no norte do Estado do Paraná: Apucaraninha, São Jerônimo, Barão de Antonina, Mococa e Queimadas.

8 De fato, a categoria jykré foi também a mim apresentada em muitos contextos kaingang com estes sentidos - aos quais, dentre outros, foi também acrescentado os de conhecimento. A expressão kanhgág jykré, por exemplo, foi a mim muitas vezes traduzida como "conhecimento kaingang". Trata-se, no entanto de uma categoria de amplo campo semântico, a qual já foi a mim também apresentada como "liderança", "estratégia”, "trançado" - e percebo haver outras traduções, a depender do contexto em que é empregada.

9 Duas variações da categoria jykré são também apontadas por Ramos (2008) como centrais para suas descrições sobre a jurisdicidade kaingang, quais seriam jykré kuryj - expressão que se aproxima da ideia de justo ou justiça - e seu oposto, jykrépãno - que se aproximaria da ideia de injustiça ou ilegalidade.

10 Percebe-se neste caso e em diversos outros contextos kaingang um processo de juridificação de regras e assuntos relativos à organização social "tradicional" - tais como a exogamia de metades e a hierarquia da liderança. Essas regras assumem o estatuto de lei ligando-se ao sistema punitivo local. No direito ocidental, o processo de transformação de normas em leis é tratado pelo termo "positivação" - seria algo passível de aproximação ao que vem ocorrendo entre os Kaingang? Uma questão a ser averiguada.

11 Sobre usos do termo “comunidade” pelos Kaingang de Rio da Várzea e alguns de seus desdobramentos, ver Gibram (2016).

12 Devo notar que, em alguma TIs kaingang, tem-se percebido a criação de estatutos escritos, listando as leis internas operantes no local. Tal é os caso, por exemplo, das TIs Inhacorá e Iraí. Em Rio da Várzea, indígenas da liderança também manifestaram o desejo de elaborar esse tipo de documento. Penso que a estabilização de leis orais para documentos escritos, bem como todos esses processos de juridificação percebidos entre os Kaingang, merecem ser mais profundamente investigados. 
considerados ideais. São falas que constituem parte fundamental, portanto, daquilo que Ramos (2008) caracterizou como "sistema jurídico kaingang". Quando alguém bebe demais, briga, causa confusão dentre outros desvios - os aconselhamentos mostram-se imprescindíveis. Segundo o falecido João Elias, "Primeiro executa, depois aconselha, porque é só com o conselho que a execução pega bem". Há casos em que as pessoas pagam seus erros na cadeia local, outros em que fazem trabalho comunitário, mas esses só têm eficácia se ocorrerem seguidos dos aconselhamentos. É de se notar que quando o erro é considerado de pouca gravidade ${ }^{13}$, o acusado leva apenas um "xingamento", seguido de aconselhamentos.

Interessante destacar que além da ingestão excessiva de bebidas alcóolicas e das brigas, é também considerado um erro falar mal das lideranças e diversos outros casos de fofoca [vẽnh vĩ korég = fala ruim de alguém]. As principais fofocas condenadas são aquelas sobre casais, que envolvem adultério. Quando esse tipo de acusação ocorre, o casal envolvido, o relator e a pessoa que foi traída são colocados frente a frente, para que se descubra quem está falando a verdade. Se constatarem que a traição foi verídica, o casal de infiéis vai preso na cadeia. Se não, condena-se o fofoqueiro.

Devo destacar, diante do apresentado, que grande parte das leis internas são voltadas ao plano familiar ou doméstico (mais especificamente, às relações conjugais) ${ }^{14}$ - isto também sendo válido ao conteúdo dos aconselhamentos, que, como já apresentado, remetem à tradição ou ao costume dos antigos. Uma dessas leis, talvez considerada a mais importante, diz respeito à regra de exogamia entre os pertencentes às metades kamé e kanhru ${ }^{15}$. Os casamentos só são aprovados pela liderança se essa condição for respeitada ${ }^{16}$.

De forma congruente, a outra ocasião específica de atuação dos conselheiros é justamente quando as pessoas se casam. A cerimônia de casamento kaingang é impressionante, um verdadeiro potlatch jê meridional, em que as partes do noivo e da noiva disputam quem fornece mais comida, bebida e, principalmente, quem queima mais foguetes. Essas festas grandiosas só saem quando se casa bem, ou seja, quando o casamento respeita a exogamia das metades kamé e kanhru e a devida distância genealógica.

$\mathrm{Na}$ TI Rio da Várzea e outras próximas a ela, a festa de casamento indígena não ocorre sem a presença e a fala dos conselheiros ${ }^{17}$. São eles também que garantem que se case bem. Como na formação da liderança, a festa de casamento conta com dois conselheiros, em geral convidados de

13 Veja-se que Ramos (2008: 184) chamou a atenção para o uso, pelos Kaingang do Tibagi, do termo kygnẽ mág [kygnẽ = erro; mág = grande] como diferenciador dos erros / kygnẽ de pouca gravidade.

14 Este aspecto aponta para o fato de que as leis internas, neste contexto, parecem aglutinar o que Ramos (2008) definiu como jykré e ki ha han ke - ou seja, tanto os planos da convenção, da tradição e do mito, quanto a boa conduta no plano da convivialidade comunitária e doméstica.

15 Os Kaingang são classificados na literatura, como os demais grupos do tronco linguístico Jê, como dualistas. O dualismo kaingang revela-se altamente expressivo na divisão das coisas do mundo - pessoas, animais, plantas, astros, espíritos - entre as metades kamé e kanhru. Esta divisão remete ao mito de origem, no qual os gêmeos Kamé - mais comprido, mais forte, mais lento, associado ao sol - e Kanhru - menor, mais ligeiro, associado à lua - criam os Kaingang e todas as coisas do mundo (cf. Crépeu 1997, 2006). Para as relações inter-humanas, o pertencimento às metades Kamé e Kanhru é patrilinear e estabelece regra de casamento exogâmica. Conferir, sobre teorias nativas sobre as regras e normas de parentesco, Gibram (2012); para a descrição dessas regras em diversos contextos kaingang, cf. Veiga (1994).

16 Refiro-me aqui especialmente em relação à TI Rio da Várzea, no entanto, esta constatação é válida para diversas outras TIs kaingang do Rio Grande do Sul.

17 Importante destacar que Ramos (2008: 186) aponta a imprescindibilidade dos aconselhamentos também no caso de separações de casais. Como também aqui apontado, uma vez que separações são consideradas um erro, a eficácia dos aconselhamentos nestes casos se apresenta e se coaduna com outras formas de condena. 
outras aldeias, sendo um da mesma metade do noivo e um da mesma metade da noiva (refiro-me às metades kamé e kanhru). O ápice da festa ocorre com a disputa de foguetes, realizada em cortejo. A este embate, seguem-se os momentos das falas dos conselheiros direcionadas aos jovens noivos. Após os aconselhamentos, segue-se a fala do cacique, direcionada a todos os convidados presentes.

Nos aconselhamentos durante o casamento, os conselheiros enfatizam o respeito à exogamia das metades, as boas relaçóes com os jamré [cunhados ou aqueles que pertencem a metades diferentes], o respeito para com os kakré [sogros e sogras, incluindo aqueles mais velhos de metades diferentes à própria], apontando essas relações como a base da vida kanhgág, aquilo que organiza o viver em comunidade desde o tempo dos antigos [vãs ỹ]. Além disso, reiteram seus compromissos e o respeito com seu noivo/noiva, as mudanças na forma de vida após o casamento, os cuidados que deverão ter com os filhos, com o sustento da casa, com os alimentos e demais providências domésticas. Diz-se que o aconselhamento garante que o casamento seja eficaz, que dure; garante, enfim, que se case bem.

Pude participar de duas festas de casamento na TI Rio da Várzea, no ano de 2011 e no ano de 2013. Traduzi trechos de aconselhamentos de forma simultânea, com a ajuda de algumas de minhas amigas kaingang ali presentes. Outros trechos foram registrados em audiovisual feito por mim por solicitação dos noivos. Importante ressaltar que as falas de aconselhamentos são, nestes contextos, proferidas por pessoas da mesma metade que àquelas a quem essas falas são dirigidas. Abaixo trago um dos trechos de um aconselhamento no casamento realizado em maio de 2013, por um conselheiro da metade kanhru, dirigindo-se ao noivo, também da metade kanhru:

Uri ã tóg prünh kefi mrénĩ.

[Hoje você está com a mulher que vai ser sua esposa.]

Uri ã kakrã vin ve ã tóg compromisso han mũ.

[Hoje seu sogro dá um compromisso grande para você assumir.]

Uri ã tóg ã jykre fi mãn ke nĩ.

[Hoje você vai ter que refazer seu pensamento.]

A pié tỹ gĩ jẽ ha. Mog kãn ã tóg mũ.

[A partir de agora você não é mais criança, você é um homem crescido.]

Ũri ég rike ã tóg nĩ ha.

[Hoje você é igual a nós.]

Uri ã jykre hãn ã tóg mũ.

[Hoje você está fazendo teu pensamento.]

Hẽ ri ken kỹ ?

[Masporque?]

Uri ã tóg ã kakrã kósin fi mrénĩ.

[Hoje você está com a filha do teu sogro.]

Uri ã compromisso tóg mág nĩ. 
[Hoje teu compromisso égrande.]

A tỹ ã kakrã mré compromisso tag han vĩ tỹ ã tỹ égjóg mág mré compromisso han ri ke ni.

[Firmar esse compromisso perante teu sogro é como se estivesse firmando um compromisso com nosso paimaior.]

(...)

Nén'ũ tỹ fi mỹ tũ nĩ kỹ fi tóg mỹ a ke nĩ.

[Se faltar alguma coisa, ela vai ficar com vergonha.]

A tỹ fi mỹ nén 'ũ hãn tu nĩ kỹ fi hẽri ken kỹ ã mỹ hãn ke mũ gé?

[Se você não fizer nada para ela, como ela vai fazer alguma coisa pra você??]

Äjóg rike ã jënh ke nĩ ha.

Você term um exemplo como teu pai.

Nén 'ü kóken mág ti, kir inh jé [três meses] kysã tagtukäki ajag tüjagnẽ vãmke mẽ he, ün tatá üfi tugrin. [Ele teve uma despesa grande, não quero saber de conversas dentro de três meses falando que você já quer se separar, arrumar outra mulher.]

A jóg vĩ nĩ, ãjóg kofá ke gé.

[Teu pai está aqui, teu tio está aqui também.]

A vejé ag tóg kãmũ mũ. Áprũ fi tóg ã mré kã nĩ gé.

[Vieram de longe pra te ver. Tua mulher está aqui com você agora.

Kanhró ã jẽ!!

[Você é inteligente!]

Jykré há ajag nỹtĩ.

[Você e ela têm as leis \{sistema, liderança\}].

Jagy ti tĩ, ã kanbkã ag vỹ kuvar tá kamujẽg, ã ve je. A régre fag, ã jamré ág ke gé. [É difícil, teus parentes vieram de longe pra te ver. Tuas irmãs, teus cunhados também.]

Uri ã compromisso tóg mág nĩ, ã kakrã tóg ã vẽgnĩ ni.

[Hoje teu compromisso é grande, teu sogro está ali sentado te olhando.]

Uri ã tóg ã jykre fi mãn ke nĩ.

[Hoje você está repensando tua conduta (...) $]^{18}$

É de se notar que existem elementos formais nos aconselhamentos que remetem a características típicas de artes verbais ameríndias, tais como a repetição e um certo grau de paralelismo - neste

18 Transcrição realizada com o auxílio da pesquisadora indígena Goj Kuitá, estudante do curso de Licenciatura Indígena da UFSC e habitante da TI Apucaraninha, no Paraná. Saliento que podem ser encontradas algumas diferenças na grafia das palavras devido às diferenças dialetais no Paraná e no Rio Grande do Sul, que serão destacadas em trabalhos posteriores. De acordo com Wiesemann (1978), a língua kaingang subdivide-se em cinco dialetos regionais. 
exemplo, notados pela repetição de frases começadas com üri [hoje] e pelo espelhamento de frases inteiras, como "Ũri ã compromisso tóg mág nî̀" [Hoje teu compromisso é grande]. Estes elementos serão aprofundados em trabalhos posteriores, a partir de um volume maior de transcrições e exemplos comparativos.

\section{Falas de chefe gradativas}

É importante destacar o fato de que os aconselhamentos kaingang, além de serem falas "para dentro“ - ou seja, falas proferidas entre e para os Kaingang, e não para os brancos [fóg] ou outros indígenas - são falas direcionadas a uma só pessoa por vez. Eles são uma espécie de ensinamento, uma lição de fala, passada de alguém mais velho e mais sábio - kanhró - para alguém mais jovem, inexperiente, que está prestes a se casar ou que tenha cometido erros de conduta. Nisso os aconselhamentos se diferem das clássicas falas de chefe, sobre as quais disserta Clastres especialmente no artigo "O dever da palavra" (Clastres 2003[1963]), ou nos fala Bruce Albert e Davi Yanomami (Kopenawa \& Albert, 2010) a respeito das falas tipo hereamuu, entre tantos outros exemplos etnográficos.

Falas de chefe são falas públicas, genéricas, dirigidas a toda a comunidade. Além disso, são falas que podem tanto ser "para dentro" quanto "para fora": são crescentes os contextos em que as lideranças indígenas são requeridas para falar aos brancos e a outros indígenas, em eventos públicos supralocais, nos quais os chefes também proferem formas específicas de fala, que geralmente assumem o aspecto de "falas duras" (cf. Gallois 2000). Neste artigo, Gallois justamente problematiza as falas políticas dos Wajãpi destinadas aos brancos, enfatizando tratar-se de transformações de falas de chefes, bem como de narrativas míticas.

Entre os Kaingang, as falas de chefe "para dentro" ocorrem nas reuniões do cacique com toda a comunidade. Essas reuniões são em muitas TIs realizadas uma ou duas vezes por mês para apresentar ou discutir problemas relativos ao cotidiano do coletivo, ou por algum motivo extraordinário, como a troca de alguma liderança. Nessas reuniões fazem-se presentes mulheres, homens, crianças, idosos. $\mathrm{Na}$ TI Rio da Várzea, mulheres e homens dispunham-se diametralmente opostos no recinto onde ocorria a reunião, sentados em bancos de madeira ou no chão. Os membros da liderança sentavam-se em cadeiras, em um ponto demarcado entre os homens. $\mathrm{O}$ cacique, posicionado ao centro como principal orador da reunião, falava por aproximadamente três horas - sendo muitas vezes interrompido por alguns dos conselheiros, por comentários ou por risadas dos demais presentes. Os momentos em que apenas ele falava eram raros.

As reuniões da liderança - às quais pude sempre acompanhar apenas paralelamente, visto serem consideradas ocasiões de participação estritamente masculina - também apresentavam configuração discursiva similar: dificilmente apenas uma pessoa falava sozinha, sendo o mais comum dois ou três 
falarem ao mesmo tempo ${ }^{19}$. Pude observar essas reuniões na TI Rio da Várzea, na TI Queimadas e na TI Mococa (estas últimas localizadas no Paraná), onde paralelamente a elas, as mulheres também se reuniam para conversar, destalar e trançar taquaras para a confecção de cestos e peneiras.

Além de tratar dos assuntos e dos problemas conjunturais, as falas do cacique nas reunióes de comunidade que pude participar remetiam sempre às leis internas, e às condutas morais dos antigos. Constata-se, portanto, que os conteúdos das falas do cacique e aqueles dos aconselhamentos apresentam em grande medida temas similares, com a diferença de que, nos aconselhamentos, o imperativo se dá na primeira pessoa do singular: você deve se comportar bem, ter respeito por sua esposa/ marido, respeitar seu sogra/sua sogra, respeitar as lideranças, respeitar os antigos, não fazer fofoca. As falas de chefe kaingang - no caso, as falas do cacique quando reúne toda a comunidade ao seu redor - apresenta esses mesmos conteúdos, sendo, no entanto, destinadas a todos presentes, a toda comunidade.

Desta forma, penso que os aconselhamentos kaingang podem ser considerados como falas de chefe em uma menor escala. Ou seja: seriam como falas de chefe distribuídas no cotidiano da aldeia, de forma gradativa, dirigidas a uma pessoa por vez. Falas de chefe escalares, com os mesmos conteúdos - que todos já sabem, mas que precisam ser falados pelas lideranças, não apenas pelo fato de que as lideranças "devem" essas palavras ${ }^{20}$-, essas palavras, assim como as falas do cacique, fazem coisas, criam vínculos com os antigos e o tempo do vãs y (tempo antigo), criam continuamente o mundo no ũri (tempo atual), transmitem continuamente conhecimentos que não podem ser esquecidos, sob a pena de ser também esquecido o modo de ser verdadeiramente indígena, de ser kanhgág pé.

Veja-se que, no entanto, as performances das falas de aconselhamento e de falas de chefe/cacique diferenciam-se em diversos pontos. $\mathrm{O}$ ato de fala do cacique, por não ser direcionado a uma só pessoa, apresenta gestuais de ênfase às próprias palavras; além disso, o cacique por vezes fica andando de um lado ao outro, muito provavelmente para que todos ouçam o que está dizendo. Os conselheiros, por sua vez, constroem seus atos de fala com apontamento de dedos à pessoa que é aconselhada, e falam em pé, parados, próximos ao ouvinte. $\mathrm{O}$ aconselhado geralmente fica sentado, ouvindo o aconselhamento de cabeça baixa, sem direcionar seu olhar para o conselheiro. Vale também destacar o fato de que no aconselhamento não se percebe a obliteração sonora do emissor. Essa obliteração, no entanto, se dá no plano da autoria dessas falas, uma vez que o conteúdo das mensagens dos aconselhamentos é atribuído aos antigos, e não à pessoa que aconselha.

19 O aspecto discursivo kaingang de obliteração do indivíduo emissor parece-me passível de comparação com o que Graham (1993) apresenta em relação aos Xavante, em suas performances nas reuniões de liderança política conhecidas como warã. Neste contexto, a autora destaca que o discurso xavante se configura como um fenômeno extra individual, tratando-se de uma produção coletiva, formada por múltiplas vozes. No warã, que ocorre à noite, os participantes sentam-se de costas um para o outro, evitando identificar quem são os emissores de cada fala. Além disso, simultaneamente às falas de cada emissor, outros presentes também falam ou emitem sonoridades enunciativas que correspondem à concordância do discurso dos emissores, havendo uma colagem de múltiplas vozes em repetição. O discurso, então, produz-se ali de forma dialógica, o orador não se torna totalmente responsável por ele: muitas vezes sua fala é completada por outro emissor, ou acrescida de sons, interjeições e repetições de partes já proferidas. O ponto a ser destacado é que a sobreposição de vozes, os murmúrios e as falas simultâneas não são considerados interrupções ou distúrbios comunicativos, mas colaborações para o discurso produzido nesta arena, coletivamente.

20 Refiro-me aqui ao tratamento de dever conferido por Clastres 2003[1963] às palavras dos chefes indígenas. Sua proposta é que as palavras funcionariam como valor de troca à sociedade por alguns atributos privilegiados da chefia, dentre eles, o direito à poligamia. 
Cumpre destacar que uma das formas como traduzem aconselhamento aponta para o plano pragmático desta forma de fala. Disse-me minha professora de kaingang em Rio da Várzea que o termo mỹge ke há é utilizado para quem dá e recebe o conselho. Aponta para a eficácia do conselho, de que ele deu certo como uma lição. Aqui o sufixo há é colocado como algo que qualifica as ações ou os objetos como bom, bonito, favorável, que deu certo. A expressão, por outro lado, que utilizam para o aconselhamento que não pegou, não deu certo, ou não foi apreendido pelo receptor é mỹge ke korég. Korég é o qualificativo utilizado para conferir as qualidades de ruim, mal, feio, errado.

Esta denotação do aconselhamento entre os universos semânticos há e korég permeia também o conteúdo do que é transmitido, uma vez que o que é qualificado como há remete ao que é bom, bonito, sadio - aquilo que é valorizável -, em contraposição ao que é korég - feio, ruim, que traz malefícios. Esses qualificativos podem ser tanto atribuídos a pessoas e coisas, como também às práticas, às quais se voltam especialmente os aconselhamentos. Ser respeitoso, agir como os antigos, seguir as leis internas, faz parte do que seria há. Beber demais, causar confusões, desrespeitar as lideranças e os mais velhos, korég. Veja-se que na TI Apucaraninha, o termo que utilizam para o que entendemos como aconselhar éjyvẽn, e vẽnh jyvẽn [vẽnh = de alguém] para aconselhamento ${ }^{21}$.

Interessante notar o paralelo com o que foi descrito por Keese dos Santos (2017) a respeito dos aconselhamentos guarani - nhemongueta. Segundo o autor, essas falas proferidas pelos mais velhos atualizam a oposição vai e porã, o primeiro termo apontando para o que é perecível, feio, agressivo e o segundo para o divino, imperecível, belo. Veja-se que o autor salienta o cuidado em não se cristalizar a oposição guarani vai/porã em conteúdos morais - o que, em certo sentido a distancia da oposição hál korég kaingang, que, mesmo não sendo também cristalizada em aspectos intransmutáveis, fundamenta, entre tudo o que pode ser qualificado por esta oposição, também princípios de moralidade. Por outro lado, se nos aconselhamentos kaingang se tem como referência os modos de vida dos antigos no tempo do vãs ỹ, entre os Guarani, enfatiza-se o modo de vida deixado pelas “divindades":

"Nesses discursos são enfatizados justamente os preceitos relacionados ao teko porã (modo de vida deixado pelas divindades), ao comedimento, à generosidade (mborayvu), às regras matrimoniais (-mendakuaa), ao uso correto do idioma (ayvukuaa), aos alimentos verdadeiros (tembiu etéi) e à importância dos cantos (mboraei), danças (jeroky) e rezas (tarova). Os enunciados negativos que aparecem nos discursos normalmente são reprovações à falta de generosidade com os parentes, a ter comportamentos coléricos como de inimigos (-vaija) e a viver de modo parecido com os não indígenas (jurua reko)." (Keese dos Santos, 2017: 236).

Devemos nos atentar, no entanto, para o fato acima pontuado de que o conhecimento dos antigos veiculado entre os Kaingang pelos aconselhamentos não é circunscrito aos planos de relacionalidade apenas humana, uma vez que é permeado de conhecimentos do mato, aos quais se atribui, conforme a fala acima apresentada de Jorge Garcia, os ensinamentos dos mestres da mata, dos jagrẽ, e de outros seres além do humano.

21 Ramos (2008) aponta também a categoria vẽnh vĩ [fala de alguém], destacando o estatuto contratual ou de compromisso estabelecido por meio de falas verdadeiras. Outras categorias relacionadas à fala apontadas pela autora são: vênh vĩ korég [fala ruim de alguém], expressão traduzida como fofoca (expressão também encontrada no contexto de Rio da Várzea); e vĩ vĩ he, expressão que a autora aproxima à ideia de "denúncia" (:154). 


\section{Ordem e desordem; festa e silêncio}

Como vimos, os aconselhamentos kaingang são uma veiculação do que denominam de leis internas - leis que não são escritas e que, portanto, devem ser faladas e ouvidas, passadas dos mais velhos aos mais novos, reafirmadas nas falas dos conselheiros, em ocasiões específicas. Vimos, ademais, que o conhecimento dos antigos é passado também dentro das casas, ao redor dos fogos, pelos kofá kanhró (pessoas mais velhas e sábias), muitas vezes reconhecidos como troncos-velhos dali - pessoas de idade avançada, que viveram e tiveram seus umbigos enterrados naquele território, onde provavelmente seus ascendentes foram também enterrados.

Os conselheiros, geralmente anciãos, veiculam uma moralidade considerada exemplar, a qual associam em grande parte ao sistema dos antigos. Esta moralidade contém em si a noção de desvio, e os aconselhamentos são apenas concebíveis em relação à possibilidade do erro. Em suma, através dos aconselhamentos, sustenta-se e reitera-se como os Kaingang do üri [tempo atual, hoje] idealmente devem agir, de acordo com os preceitos, os modos de agir do vãs y [tempo passado, dos antigos]. São, como vimos, variações de falas do chefe, destas últimas diferenciando-se em termos escalares.

Quero por fim sinalizar que essa noção ideal de conduta dos antigos é em grande parte associada à noção de ordem. Segundo D. Gilda Kuitá, “os Kaingang no passado eram muito organizados”. Essa ordem, seguindo o que foi falado por ela nos dias do seminário "Lições de Fala", é vivenciada e atualizada no ritual do Kiki, uma festa onde os pertencentes das metades kamé e kanhru pintam-se segundo suas marcas, ra tej e rá rór ${ }^{22}$, bebem o kiki - um hidromel potencializado atualmente com ervas e cachaça -, cantam e dançam para satisfazerem os espíritos dos mortos [vénh kupri] para que estes voltem para sua aldeia [vẽnh kupri iamõ ou numbe - a aldeia dos mortos] ${ }^{23}$. Segundo D. Gilda, o Kiki deve ser realizado quando as comunidades estão muito desorganizadas, com muitos problemas, muitas brigas e desarticulações internas. "Ele é a ordem do índio. Porque a desordem vem quando os espíritos dos mortos estão rondando..." - disse-me ela.

D. Gilda disse também, em sua apresentação no Seminário “Lições de Fala”, que o SPI ${ }^{24}$ silenciou muitas vozes kaingang: as vozes dos kujá, dos cantos, das festas e rituais, das memórias dos velhos. Sua

22 "Marca comprida" e "marca redonda", associadas, respectivamente, às metades kamé e kanhru. Essas denominações, devo enfatizar, são encontradas nas aldeias do Rio Grande do Sul. Na TI Apucarana, onde mora D. Gilda, assim como nas outras aldeias a esta relacionadas pelo complexo da bacia do Tibagi (TIs Barão de Antonina, São Jerônimo, Mococa e Queimadas), a "marca redonda" (rá rór) é designada como rá kutu, e a marca comprida (rá téj) é designada como rá jojo.

23 Para descrições do Kiki ver, principalmente, Veiga (1994, 2000), que o etnografou na TI Xapecó (SC). Ver também as descrições de Baldus (1937) - que o chamou de "culto aos mortos" - na TI Palmas (PR). Amoroso (2014) traz, a partir dos registros de frades capuchinhos, descrições de um enorme Kiki realizado no aldeamento de São Pedro de Alcântara para o famoso cacique Manoel Arepquembe, no final do século XIX. Nas obras de Crépeau (1997), Tommasino $(1995,2000)$ e Fernandes $(1998,2003)$ encontram-se relatos da realização desta festa funerária em diversas aldeias kaingang no começo do século XX. A partir da metade deste século, o Kiki passou a ser realizado apenas na TI Xapecó (SC), onde havia sido feita pela última vez no ano 2000, voltando a ser realizada em março de 2018. O Kiki foi também realizado na TI Kondá, em maio de 2011, onde pude presenciar um dos fogos, ou seja, uma das etapas do "ritual".

24 Serviço de Proteção aos Índios, órgão indigenista antecedente à FUNAI, que tinha como principal intuito transformar os indígenas em trabalhadores rurais. As aldeias Kaingang foram um dos principais "alvos" de ação do SPI, o qual deixou marcas profundas na organização sociopolítica desses indígenas, como a militarização da liderança e as formas de punição como a cadeia, hoje encontradas em praticamente todas as TIs kaingang. 
fala nessa ocasião lembrou-me o que ela havia dito durante a Festa do Pãri, na TI Apucarana, organizada por ela e pelo grupo Nén Ga:

"sabe por que eles proibiram nós os Kaingang de fazer nossas festas e nossos rituais? Porque durante as festas a gente vira a noite, passa os dias comendo junto, dormindo junto. Ai nem lembra de trabalhar. E eles queriam era escravizar os indios com o trabalho...”. (D. Gilda, março de 2018)

Assim, o que veio a ser imputado pelo SPI sob a insígnia da ordem, da civilização e do progresso nacional trouxe desordens profundas no modo de ser indígena. O Kiki deixou de ser realizado em quase todas as TIs kaingang, os kujá passaram a ser perseguidos e, por isso, muitos deles abandonaram progressivamente suas práticas (cf. Tommasino 1995). Os velhos - ainda hoje - passaram a esconder o que sabiam das práticas dos antigos, pelo medo de ser discriminados ou perseguidos, uma vez que passaram pelo crivo violento de assimilação imputada pelas práticas do SPI.

Nesta mesma desordem das coisas, foram também silenciadas, em muitos lugares, as vozes dos conselheiros. Hoje, por exemplo, não existe mais na TI Apucarana as figuras reconhecidas dos conselheiros, que dirigem seus aconselhamentos às pessoas da mesma metade que a sua, aconselham os noivos nos casamentos, influenciam decisivamente as ações a serem tomadas pelo cacique por meio de suas falas. Os aconselhamentos são hoje, na TI Apucarana, proferidos pelo próprio cacique, que aglutina em si funções políticas antes atribuídas aos conselheiros, conhecedores das leis e dos costumes dos antigos ${ }^{25}$.

Assim, diante das imposições de silêncio do SPI - e das inúmeras outras formas de violência vivenciadas pelos Kaingang em mais de três séculos de contato com os não indígenas, as falas de aconselhamento, são além de tudo, falas resistentes, falas que insistem no modo de ser kanhgág-pé. São falas que criam vínculos com a floresta, que verticalizam as relações com os antepassados, que vivenciam e revelam memórias, tantas vezes ocultadas em contextos de contato mais intenso e violento com os fóg. São falas, como vimos, para dentro, e não para fora: faladas e ouvidas pelos e para os Kaingang, e não para os brancos. São falas da diferença.

D. Gilda é reconhecida pelo coletivo de jovens Nẽn Ga como uma mentora, uma kofá kanhró que pode aconselhar aqueles que formam continuamente esse movimento que vivencia sua resistência por meio de práticas kanhgág que estavam adormecidas, como os cantos dos antigos, as danças, as pinturas corporais, as comidas, as festas. D. Gilda passou todo o tempo do Seminário "Lições de Fala" ouvindo atentamente, em silêncio, o que os outros convidados falaram. No momento certo de sua fala, dissertou sobre os mundos e as falas kaingang e aconselhou os fóg a ouvirem mais, perguntarem menos, serem mais respeitosos. Elogiou o que foi apresentado nos dias anteriores e aconselhou, por fim, os parentes indígenas a continuarem praticando suas brincadeiras, suas festas, seus cantos. Assim como faziam seus antigos.

\section{Paola Andrade Gibram é doutoranda no Programa de Pós-Graduação em An- tropologia Social da USP (PPGAS/USP).}

25 Segundo diversos interlocutores, a aglutinação de funções na figura do cacique e a forma como tem "administrado" atualmente a comunidade também foram decorrentes do contato com os fóg e das imposições do SPI. 


\section{REFERÊNCIAS BIBLIOGRÁFICAS}

AMOROSO, Marta Rosa. 2014. Terra de Índio: imagens em Aldeamentos do Império. São Paulo: Terceiro Nome.

BALDUS, Herbert. 1937. Ensaios de etnologia brasileira. São Paulo: Editora Nacional.

CLASTRES, Hélène. 1975. A terra sem mal: profetismo tupi-guarani. São Paulo: Brasiliense.

CLASTRES, Pierre. 2003 [1963]. A Sociedade contra o Estado: Pesquisas de Antropologia Politica.

Rio de Janeiro: Francisco Alves.

CLASTRES, Pierre. 2004 [1976]. Arqueologia da Violência - pesquisas de antropologia política. São Paulo: Cosac \& Naify.

CRÉPEAU, Robert R. 1997. “Mito e ritual entre os índios Kaingang do Brasil Meridional”. Horizontes Antropológicos 3(6): 173-86.

CRÉPEAU, Robert R. 2002. "A Prática do Xamanismo entre os Kaingang do Brasil Meridional: uma breve comparação com o xamanismo Bororo”. Horizontes Antropológicos 8: 113-129.

FERNANDES, Ricardo Cid. 1998. Autoridade Política Kaingang: um estudo sobre a construção da legitimidade politica entre os Kaingang de Palmas/Paraná. Dissertação de mestrado, Programa de Pós-graduação em Antropologia Social, Universidade Federal de Santa Catarina.

FERNANDES, Ricardo Cid. 2003. Política e Parentesco entre os Kaingang: uma análise etnológica. Tese de doutorado, Programa de Pós-graduação em Antropologia Social, Universidade de São Paulo. GALLOIS, Dominique. 2000. "Nossas falas duras: discurso político e auto-representação wajãpi”. In: Pacificando o branco: cosmologias do contato no norte-amazônico, org. B. Albert, B. \& A. Ramos. São Paulo: UNESP.

GIBRAM, Paola Andrade. 2008. KAGMA TI EG KÃ KI: Um estudo panorâmico sobre a música dos indios Kaingang da T.I. Xapecó. Trabalho de Conclusão de Curso, Ciências Sociais, Universidade Federal de Santa Catarina.

GIBRAM, Paola Andrade. 2012. Politica, parentesco e outras Histórias kaingang: uma etnografia em Penhkár. Dissertação de mestrado, Programa de Pós-graduação em Antropologia Social, Universidade Federal de Santa Catarina.

GIBRAM, Paola Andrade. 2016. Penhkár: politica, parentesco e outras histórias kaingang. Curitiba: Editora Appris/ Instituto Brasil Plural.

GIBRAM, Paola Andrade. 2017. "Propostas cosmopolíticas e resistência indígena: um convite às festas kaingang”. Revista Cadernos de Campo, 26(1): 132-150.

GRAHAM, Laura R. 1993. "A public sphere in Amazonia? The depersonalized collaborative construction of discourse in Xavante". American Ethnologist 20(4):717-741.

KEESE DOS SANTOS, Lucas. 2017. A esquiva do xondaro: movimento e ação política entre os Guarani Mbya. Dissertação de mestrado, Programa de Pós-graduação em Antropologia Social, Universidade de São Paulo.

KOPENAWA, Davi e Albert, Bruce. 2010. A queda do céu: palavras de um xamã yanomami. São Paulo: Companhia das Letras. 
MENEZES BASTOS, Rafael José de. 2013. A festa da Jaguatirica: uma partitura critico interpretativa. Florianópolis: Editora UFSC.

RAMOS, Luciana Maria de Moura. 2008. Vénh Jykré e Ke Há Han Ke: permanência e mudança do sistema jurídico dos kaingang no Tibagi. Tese de doutorado, Programa de Pós-graduação em Antropologia Social, Universidade de Brasília.

ROSA, Rogério R. G. 2005. Os Kujãs são diferentes: um estudo etnológico do complexo xamânico dos Kaingang da Terra Indígena Votouro. Tese de doutorado, Programa de Pós-graduação em Antropologia Social, Universidade Federal do Rio Grande do Sul.

SEEGER, Anthony. 2015. Por que cantam os Kĩsêdjê? Uma antropologia musical de um povo amazônico. São Paulo: Cosac Naify.

TOMMASINO, Kimiye. 1995. A História dos Kaingang da bacia do Tibagi. Uma sociedade Jê

Meridional em movimento. Tese de Doutorado, Programa de Pós-graduação em Antropologia Social, Universidade de São Paulo.

VEIGA, Juracilda. 1994. Organização social e cosmovisão Kaingang: uma introdução ao parentesco, casamento e nominação em uma sociedade Jê Meridional. Dissertação de mestrado. Campinas: Universidade Estadual de Campinas.

VEIGA, Juracilda. 2000. Cosmologia e práticas rituais Kaingang. Tese de Doutorado. Campinas: Universidade Estadual de Campinas.

WIESEMANN, Ursula. 1978. "Os dialetos da língua Kaingang e o Xokleng”. Arquivos de Anatomia e Antropologia III(III): 199-217. 
Resumo: Trato neste texto dos aconselhamentos kaingang, falas proferidas por pessoas detentoras do que concebem como conhecimento dos antigos. Para isso, trago descrições etnográficas que articulam aspectos de moralidade, de parentesco e aliança, bem como aspectos ligados à ação da liderança entre os Kaingang da T.I. Rio da Várzea (RS). Minha experiência nesta localidade levou-me a perceber que o casar bem - forma ideal de aliança matrimonial, que segue a exogamia de metades e o devido distanciamento genealógico - só ocorre com a presença e a performance de conselheiros na cerimônia de casamento. A eficácia plena das punições locais, por sua vez, dirigidas àqueles que infringem as leis internas, é da mesma forma atribuída aos aconselhamentos. Destaco também o fato de que as falas formalizadas (aconselhamentos e falas de chefe) ligam-se a formas bastante específicas de conhecimento; são reflexões sobre modos de ser kanhgág pé, revelando-se, portanto, como falas da diferença.

Palavras-chave: Aconselhamentos; moralidades indígenas; formas de conhecimento; políticas indígenas; Kaingang.

\section{SPEECHES OF DIFFERENCE: COUNSELING AND WAYS OF BEING KANHGÁG PÉ}

Abstract: In this text I deal with the Kaingang counseling, speeches made by people who hold what they conceive as knowledge of the ancients. For this, I bring ethnographic descriptions that articulate aspects of morality, kinship and alliance, as well as aspects related to the action of leadership among the Kaingang of T.I. Rio da Várzea (RS). My experience in this locality led me to realize that the marrying well - an ideal form of marriage alliance that follows the exogamy of halves and due genealogical distancing - only occurs with the presence and performance of counselors in the wedding ceremony. The full effectiveness of local punishments, in turn, directed to those who break the internal laws, is similarly attributed to counseling. I also highlight the fact that formalized speeches (counseling and chief's speech) is linked to very specific forms of knowledge; it is a reflections on ways of being kanhgág $p e ́$, thus revealing itself as speeches of difference.

Keywords: Counseling; indigenous moralities; forms of knowledge; indigenous politics; Kaingang.

RECEBIDO: $04 / 11 / 2019$

APROVADO: $20 / 04 / 2020$ 
60 CAMpos V21 N.1 p. 43-59 jan.jun.2020 